\title{
Alpha I antitrypsin to treat lung disease in alpha I antitrypsin deficiency: recent developments and clinical implications
}

This article was published in the following Dove Press journal: International Journal of COPD

\author{
Kenneth R Chapman' \\ Joanna Chorostowska- \\ Wynimko \\ A Rembert Koczulla ${ }^{3}$ \\ Ilaria Ferrarotti ${ }^{4}$ \\ Noel G McElvaney ${ }^{5}$ \\ 'Department of Medicine, University \\ of Toronto, Toronto, ON, Canada; \\ ${ }^{2}$ Department of Genetics and Clinical \\ Immunology, National Institute of \\ Tuberculosis and Lung Diseases, \\ Warsaw, Poland; ${ }^{3}$ Department of \\ Medicine, Pulmonary and Critical \\ Care Medicine, University Medical \\ Center Giessen and Marburg, \\ Philipps-University, Marburg, Germany; \\ ${ }^{4}$ Center for Diagnosis of Inherited \\ Alpha-I Antitrypsin Deficiency, \\ Department of Internal Medicine \\ and Therapeutics, Pneumology Unit, \\ University of Pavia, Pavia, Italy; \\ ${ }^{5}$ Department of Medicine, Beaumont \\ Hospital, Royal College of Surgeons in \\ Ireland, Dublin, Ireland
}

\begin{abstract}
Alpha 1 antitrypsin deficiency is a hereditary condition characterized by low alpha 1 proteinase inhibitor (also known as alpha 1 antitrypsin [AAT]) serum levels. Reduced levels of AAT allow abnormal degradation of lung tissue, which may ultimately lead to the development of early-onset emphysema. Intravenous infusion of AAT is the only therapeutic option that can be used to maintain levels above the protective threshold. Based on its biochemical efficacy, AAT replacement therapy was approved by the US Food and Drug administration in 1987. However, there remained considerable interest in selecting appropriate outcome measures that could confirm clinical efficacy in a randomized controlled trial setting. Using computed tomography as the primary measure of decline in lung density, the capacity for intravenously administered AAT replacement therapy to slow and modify the course of disease progression was demonstrated for the first time in the Randomized, Placebo-controlled Trial of Augmentation Therapy in Alpha-1 Proteinase Inhibitor Deficiency (RAPID) trial. Following these results, an expert review forum was held at the European Respiratory Society to discuss the findings of the RAPID trial program and how they may change the landscape of alpha 1 antitrypsin emphysema treatment. This review summarizes the results of the RAPID program and the implications for clinical considerations with respect to diagnosis, treatment and management of emphysema due to alpha 1 antitrypsin deficiency.
\end{abstract}

Keywords: alpha 1 antitrypsin deficiency, computed tomography, emphysema, efficacy

\section{Introduction}

Alpha 1 antitrypsin deficiency (AATD) is a hereditary genetic disorder characterized by low serum levels of alpha 1 protease inhibitor $\left(A_{1}-P I\right.$; also known as alpha 1 antitrypsin $[\mathrm{AAT}])$. In healthy individuals, AAT acts to inhibit nonspecific destruction by the serine protease neutrophil elastase (NE), an enzyme that can attack lung elastin and damage bronchial and alveolar wall integrity. The most widely recognized mechanism of action is associated with protease-antiprotease imbalance hypothesis of lung disease. ${ }^{1}$ In this model, the pathogenesis of pulmonary emphysema occurs as a result of the imbalance between AAT and NE, driving excessive proteolysis that degrades alveolar and interstitial lung tissue. In patients with AATD, reduced levels of AAT result in destruction of lung tissue by NE, resulting in lung-related symptoms such as shortness of breath, wheezing, coughing and dyspnea. ${ }^{2}$ In most cases, these symptoms appear between the ages of 20 and $40 .^{3,4}$

Expression levels of AAT are determined in a codominant manner by a variety of mutations in the SERPINA1 gene. ${ }^{5}$ The normal allele PI*M is associated with the genotype PI*MM in healthy individuals and is characterized by normal
Correspondence: Noel G McElvaney Department of Respiratory Medicine, Beaumont Hospital, Royal College of Surgeons in Ireland, Beaumont Rd, Dublin 9, Ireland

Tel +353 ol 8093764

Fax +353018093765

Email gmcelvaney@rcsi.ie 
AAT levels $(20-53 \mu \mathrm{M})^{6}$ and a low risk of emphysema. Common pathogenic alleles include PI*S, PI*Z and the less-common Null alleles. Homozygosity for the PI*S allele results in moderately reduced serum levels, while the $\mathrm{PI} * \mathrm{ZZ}$ and homozygous null genotypes are associated with very low or undetectable serum AAT, respectively, and a high risk of developing rapidly progressive emphysema. ${ }^{7,8}$ The majority of patients identified with an AAT deficiency have the PI*ZZ genotype (>90\%), ${ }^{9,10}$ and these patients typically present with serum AAT levels well below the $11 \mu \mathrm{M}$ protective threshold. ${ }^{11}$ Individuals with a PI*SZ genotype may also have serum AAT concentrations below the protective threshold, whereas PI*MZ genotypes usually have concentrations within or just below the normal range. Intravenous AAT replacement therapy is the only available treatment that addresses the underlying cause of disease, aiming to raise serum levels above this protective threshold. ${ }^{12}$ Symptomatic treatments such as bronchodilators and corticosteroids have been shown to relieve symptoms of dyspnea and improve exercise capacity, but have not been shown to alter the progression of emphysema. ${ }^{13,14}$

AATD is a progressive lung disease, and early diagnosis allows patients to implement lifestyle changes and begin treatment options that slow further loss of lung tissue. However, data suggest that AATD may be underdiagnosed; evidence from screening programs in the USA suggests that fewer than $10 \%$ of patients have been diagnosed. ${ }^{15-18}$ Patients often face delays or are misdiagnosed, for example, with COPD or asthma, due to the nonspecific nature of respiratory symptoms observed with AATD. An average delay of
$5.6 \pm 8.3$ years between the initial presentation of symptoms and diagnosis has been reported, and the mean age of first diagnosis is 43.9 years. ${ }^{19}$ There is, therefore, a need to identify symptomatic patients who may benefit from treatment and those at risk who would benefit from counseling and increased monitoring. Physicians may lack awareness of the disease, available means of testing and available treatment options, further contributing to inaccurate or underdiagnosis. ${ }^{20}$ AAT replacement therapy is the only available treatment known to affect the underlying cause of the disease; however, it is not currently available in all countries.

The clinical efficacy of AAT replacement therapy was assessed in the Randomized, Placebo-controlled Trial of Augmentation Therapy in Alpha-1 Proteinase Inhibitor Deficiency (RAPID) program (Figure 1), which consisted of an initial 2-year randomized, double-blind, placebocontrolled study (RAPID-RCT [randomized controlled trial]; $\mathrm{N}=180 ; 60 \mathrm{mg} / \mathrm{kg} /$ week $\mathrm{A}_{1}$-PI or placebo) followed by a 2-year open-label extension study (RAPID-OLE [openlabel extension], $\mathrm{N}=140 ; 60 \mathrm{mg} / \mathrm{kg} /$ week $\mathrm{A}_{1}$-PI). ${ }^{21,22}$ In light of these data, and the challenges faced in the treatment of AATD, a symposium was held at the European Respiratory Society (ERS) Annual Conference 2016 to discuss these findings and recommendations for clinical practice. This review aims to explore the results of the RAPID program with respect to the use of computed tomography (CT) as a sensitive and specific measure of disease progression and its value when aiming to prove clinical efficacy. The specific features of the trial design are presented as a key component, allowing for the exploration of disease-modifying effects.

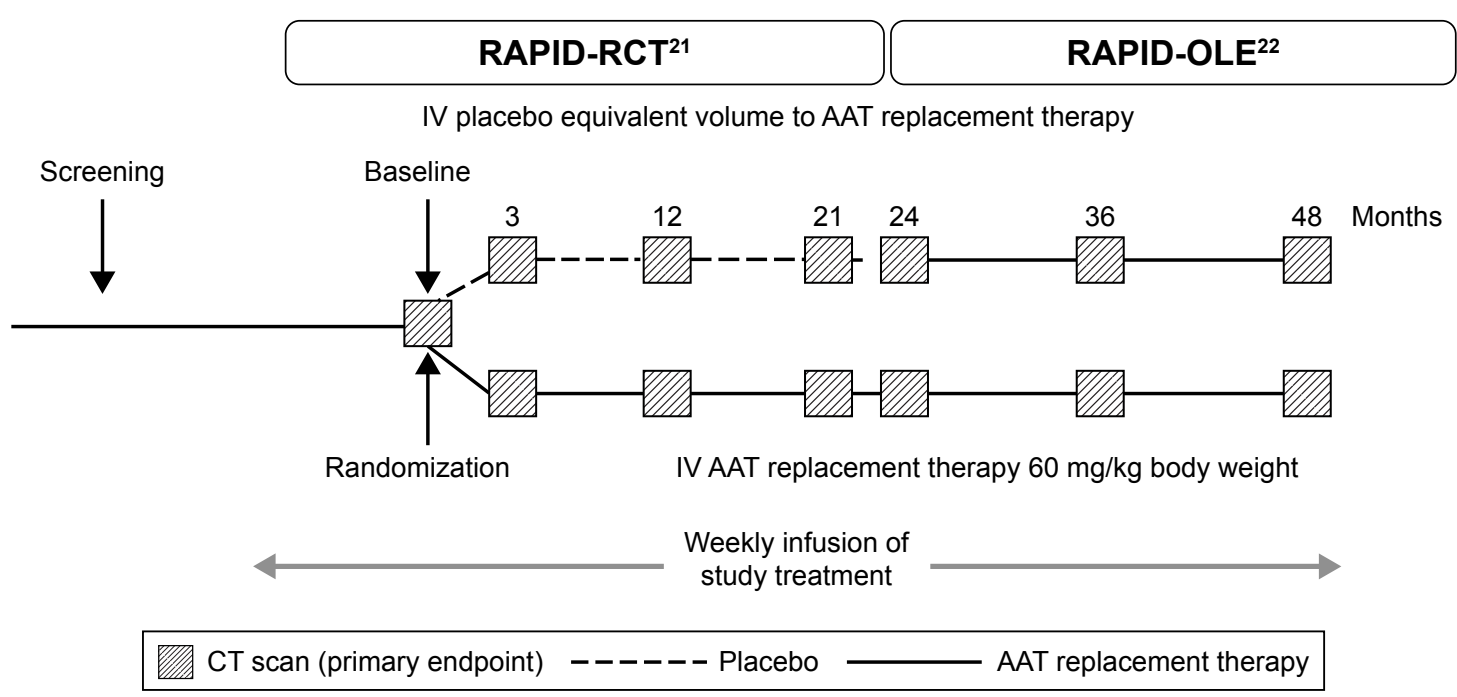

Figure I Study design of the RAPID-RCT and RAPID-OLE trials employing lung density measures by CT scans at 0, 3, I2, 2I, 24, 36 and 48 months. Abbreviations: AAT, alpha I antitrypsin; CT, computed tomography; IV, intravenous; OLE, open-label extension; RAPID, Randomized, Placebo-controlled Trial of Augmentation Therapy in Alpha-I Proteinase Inhibitor Deficiency; RCT, randomized controlled trial. 
The review focuses on the wider implications for the treatment of AATD and how new outcome measures and dose regimens, for example, $120 \mathrm{mg} / \mathrm{kg}$ weekly or every 2 weeks, can be incorporated into the current treatment landscape. Specific emphasis is placed on challenges associated with diagnosis and monitoring of patients and the timing of therapy. The review also discusses the various AAT therapy and lifestyle guidelines for AATD and how trial data may influence future treatment regimens.

\section{Discussion}

\section{Evidence for clinical efficacy of AAT - update following completion of the RAPID clinical trial program}

Early studies utilized $\mathrm{FEV}_{1}$ as a traditional surrogate marker for monitoring disease progression in COPD $;{ }^{23-25}$ however, changes in $\mathrm{FEV}_{1}$ occur slowly over time, and there are several limitations to its use. ${ }^{23}$ The RAPID trial utilized CT densitometry as a more reliable, reproducible and sensitive tool for assessing lung function decline in patients with AATD. ${ }^{23,26,27} \mathrm{CT}$ densitometry has been shown to correlate with traditional outcome measures, for example, mortality and health status, and also with $\mathrm{FEV}_{1}$ decline. ${ }^{28}$ During the RAPID-RCT, lung density decline at total lung capacity was significantly reduced in patients receiving AAT therapy compared with placebo ( -1.51 versus $-2.26 \mathrm{~g} / \mathrm{L} /$ year, respectively, $p=0.033$; Figure 2). ${ }^{21}$ After completion of the RAPID program, patients who received active therapy across all 4 years were referred to as the Early-Start group. Patients who initially received placebo during RAPID-RCT, who subsequently switched to active treatment in RAPID-OLE, were referred to as the Delayed-Start group. In RAPIDOLE, the beneficial effect of treatment over the first 2 years was maintained in the Early-Start subgroup of the patient population and remained statistically significant relative to the Delayed-Start group ( -1.63 versus $-1.26 \mathrm{~g} / \mathrm{L} /$ year at total lung capacity, $p=0.04)$. During RAPID-OLE, a statistically significant reduction in the rate of lung density decline was established in the Delayed-Start group temporal to the switch from placebo to active therapy at year two, reflecting a mean preservation of $0.52 \mathrm{~g} / \mathrm{L} /$ year $(p=0.001){ }^{22}$ Despite this, patients in the Delayed-Start group were unable to regain lung tissue lost during the placebo treatment period and did not "catch up" to patients in the Early-Start group, demonstrating a disease-modifying effect of AAT therapy in patients with AATD.

The RAPID program was the first to demonstrate significant clinical efficacy, and the findings build on evidence from previous observational studies and randomized controlled trials (RCTs; summarized in Table 1). Two previous

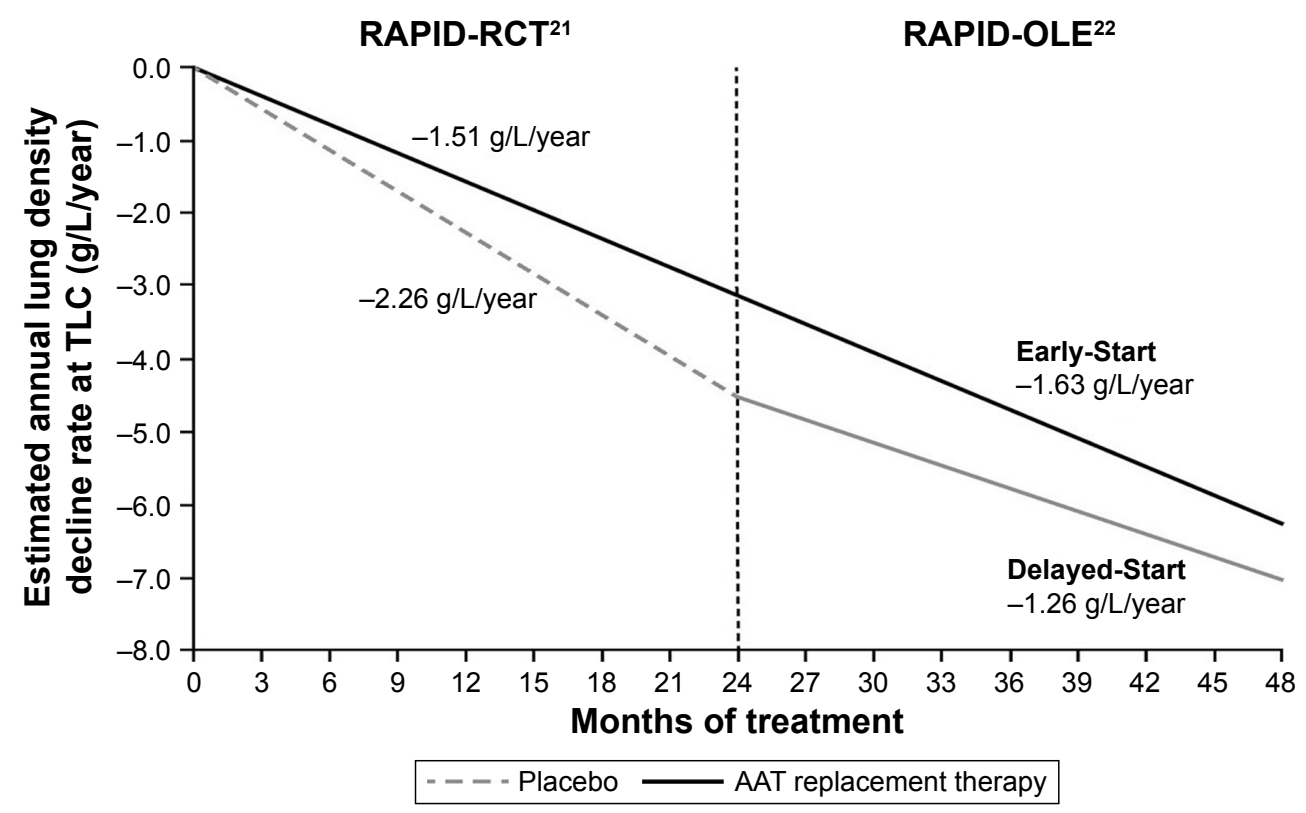

Figure 2 Annualized rate of decline in physiologically adjusted PI5 lung density $(\mathrm{g} / \mathrm{L})$ at TLC over 48 months.

Notes: Slopes estimated based on data acquired from Early-Start ( $N=75)$ and Delayed-Start ( $N=64)$ subjects who had completed both RAPID-RCT and RAPID-OLE trials. Reproduced from The Lancet Respiratory Medicine, Vol 5. McElvaney NG, et al. Long-term efficacy and safety of $\alpha$ I proteinase inhibitor treatment for emphysema caused by severe $\alpha \mathrm{I}$ antitrypsin deficiency: an open-label extension trial (RAPID-OLE), pp. 5I-60. Copyright (20I7), with permission from Elsevier. ${ }^{22}$

Abbreviations: AAT, alpha I antitrypsin; adjusted PI5, lung volume-adjusted I5th percentile of the lung density; OLE, open-label extension; RAPID, Randomized, Placebocontrolled Trial of Augmentation Therapy in Alpha-I Proteinase Inhibitor Deficiency; RCT, randomized controlled trial; TLC, total lung capacity. 


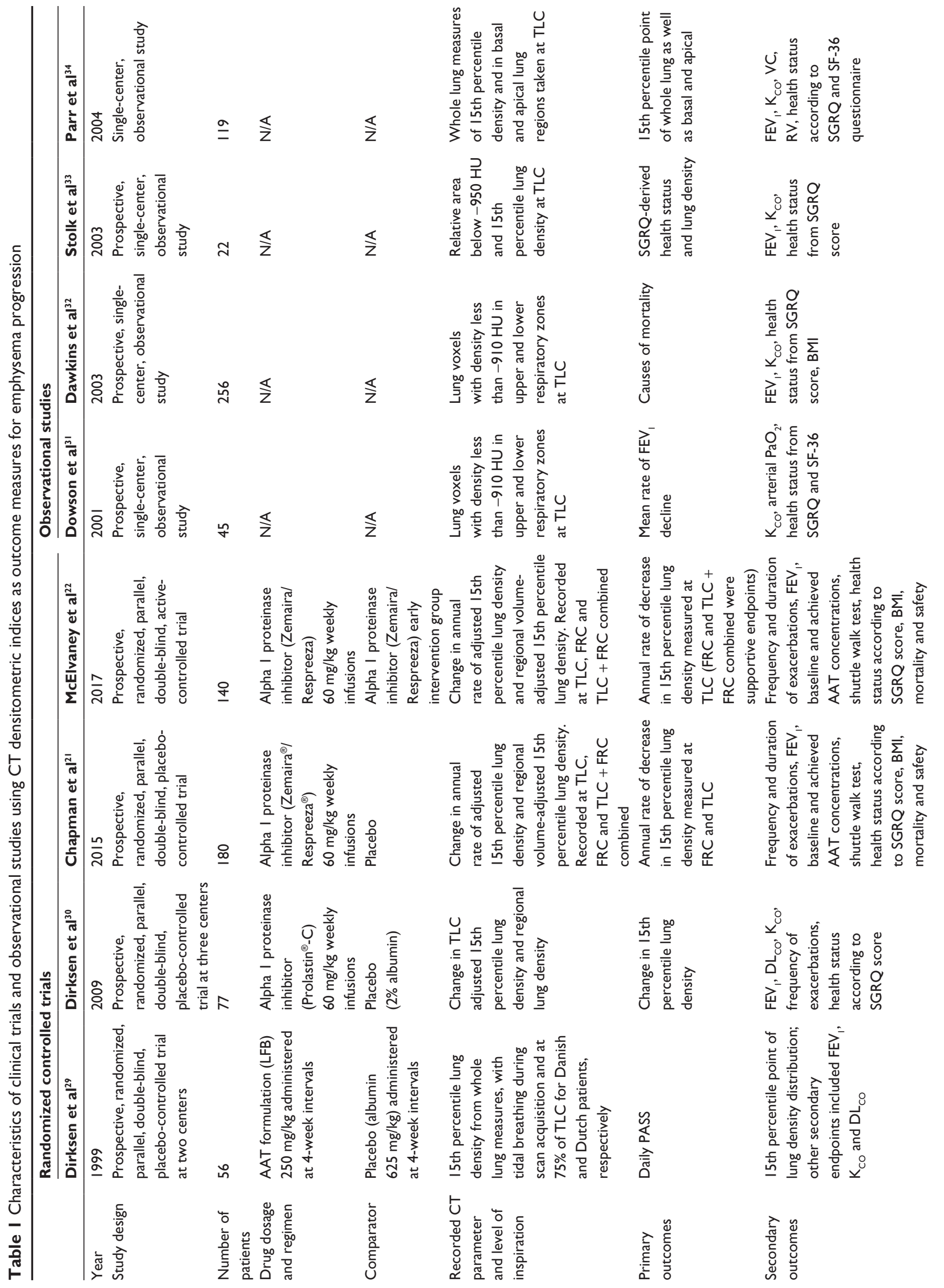



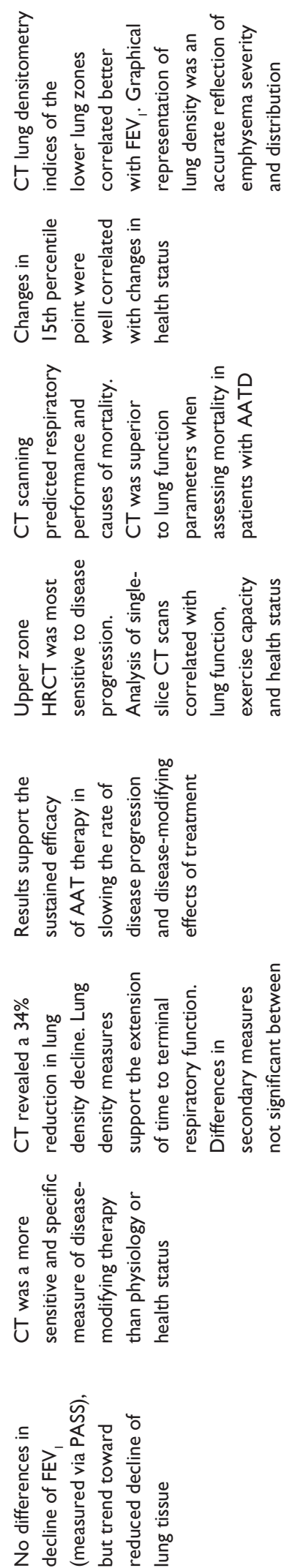

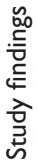

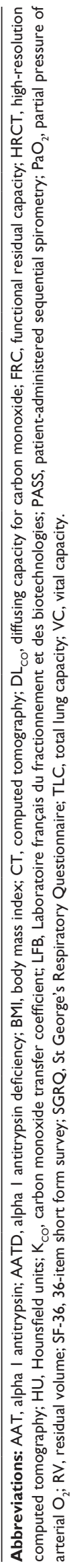

RCTs utilized CT densitometry to investigate the efficacy of AAT therapy; in the Danish-Dutch trial, 56 ex-smokers possessing an AAT deficiency of the Pi*ZZ phenotype and moderate emphysema participated in a double-blind trial of AAT replacement therapy. CT lung density measurements were used to observe a supportive trend toward protection against the loss of lung tissue in these patients after monthly administration of $250 \mathrm{mg} / \mathrm{kg}$ of AAT. ${ }^{29}$ A decade later, the EXAcerbations and Computed Tomography scan as Lung End-points (EXACTLE) trial aimed to study the use of CT densitometry as a means of ascertaining the therapeutic effect of AAT therapy using the previous trial as a basis for the study methodology. Patients with severe AATD (N=77) were randomized to $60 \mathrm{mg} / \mathrm{kg}$ weekly infusions of AAT therapy or placebo for at least 2 years. The loss of lung density in this study favored those receiving AAT therapy over the entire duration of the trial period. ${ }^{30}$ While these trials alone did not reach unequivocal statistical significance, a pooled analysis combining data from both studies indicated a significant reduction in lung density decline following AAT treatment. ${ }^{27}$

In addition to data from RCTs, there is a large body of evidence in support of clinical efficacy derived from observational studies. Several observational and registry studies have demonstrated an effect on $\mathrm{FEV}_{1}$ within specific $\mathrm{FEV}_{1}$ ranges. ${ }^{35-39}$ The largest of these studies, the AATD deficiency registry study $(\mathrm{N}=1,129)$ by the National Heart, Lung, and Blood Institute, demonstrated a significant treatment benefit in patients with severe impairment (35\%-49\% predicted) of lung function. ${ }^{37}$ Similarly, the Danish-German comparison $(\mathrm{N}=295)$ showed the most pronounced difference in the group of patients with $\mathrm{FEV}_{1} 31 \%-65 \%$ predicted. ${ }^{36}$ In a study of patients with severe AATD ( $\mathrm{N}=96)$, Wencker et al demonstrated that the greatest benefit in slowing the decline in lung function was observed in a subgroup of patients with mildly and moderately impaired lung function (baseline $\mathrm{FEV}_{1}>65 \%$ predicted), who had also been subject to a rapid decline in $\mathrm{FEV}_{1}{ }^{39}$ These findings have not been replicated in clinical studies by Dirksen et al, mainly due to smaller sample sizes and length of follow-up ( $\mathrm{N}=77,2-2.5$ years of follow-up; $\mathrm{N}=56,5$ years of follow-up). ${ }^{29,30}$ When data from these clinical studies were pooled, the rate of $\mathrm{FEV}_{1}$ decline was demonstrated to be $23 \%$ slower in patients receiving AAT therapy, with the difference predominantly seen in patients with $\mathrm{FEV}_{1} 30 \%-65 \%$ predicted. ${ }^{40}$

In addition to $\mathrm{FEV}_{1}$, earlier studies also utilized quality of life (QoL), exacerbation and mortality as endpoints for clinical efficacy in RCTs. These parameters are less sensitive 
than other endpoints, and the trials utilizing them were not suitably powered to observe a reliable difference in the clinical outcomes. As a consequence, the effect of AAT replacement therapy on these measures was not confirmed in these studies. ${ }^{29,30}$ In contrast, the AATD registry has demonstrated a statistically lower mortality rate in patients receiving AAT replacement therapy compared with nontreated subjects, an effect predominantly observed in patients with an $\mathrm{FEV}_{1}<50 \%$ predicted. ${ }^{37}$ Mortality in both mild and moderate lung disease is low; therefore, this apparent difference in mortality between patients with severe and mild lung disease is not surprising. ${ }^{32}$ These findings have not been replicated in clinical trials; much larger sample sizes and longer duration placebo-controlled trials would be needed to show a significant difference. Given the rarity of AATD, such clinical trials would be impractical. It would be difficult to recruit sufficient patients in countries where AAT is already licensed. More importantly, given the significant body of evidence which now support the efficacy of AAT therapy, the extended duration of placebo treatment is unethical.

\section{The impact and significance of disease modification in AATD}

Disease modification can be defined as an improvement or stabilization of a disease state resulting from a reduction in the rate of disease progression that occurs following therapeutic intervention, which may persist after the intervention is discontinued. ${ }^{41}$ It exerts its effects on the underlying pathology or pathophysiology of the disease, rather than the symptoms alone. The key hallmark of a disease-modifying treatment is the capacity to alter the course of the disease and have a beneficial effect on clinically significant trial endpoints (Figure 3). RAPID-RCT and RAPID-OLE were the first trials to demonstrate the disease-modifying effect of AAT replacement therapy on emphysema progression. During RAPID-RCT, patients receiving active therapy achieved statistically significant reductions in the annual loss of lung tissue as compared with those receiving placebo. Continuous active treatment over 4 years favored the Early-Start group. Upon switching to active therapy, the Delayed-Start group demonstrated a statistically significant response to therapy, while lung tissue lost during the period of placebo treatment was never regained. ${ }^{21,22}$ This demonstrates that treatment with AAT replacement therapy is disease modifying, altering the course of disease progression, which has important implications for treatment. Early intervention, particularly in patients with fast lung density decline, would be beneficial to preserve functional lung tissue. Previous clinical studies failed to demonstrate this effect due to inadequate trial design or the use of less-sensitive clinical endpoints, such as lung function/ spirometry $\left(\mathrm{eg}, \mathrm{FEV}_{1}\right){ }^{23}$ Disease modification has significant implications for the design of future clinical trials. Following publication of data from the RAPID program, there is now a large body of evidence that confirms the efficacy of AAT replacement therapy. Although clinical studies have not demonstrated significant effects on mortality, given the large number of patients required and length of follow-up, it may not be ethical or feasible to conduct further placebocontrolled studies to assess this endpoint. Owing to the slow progression of AATD, Schluchter et al estimated that a trial

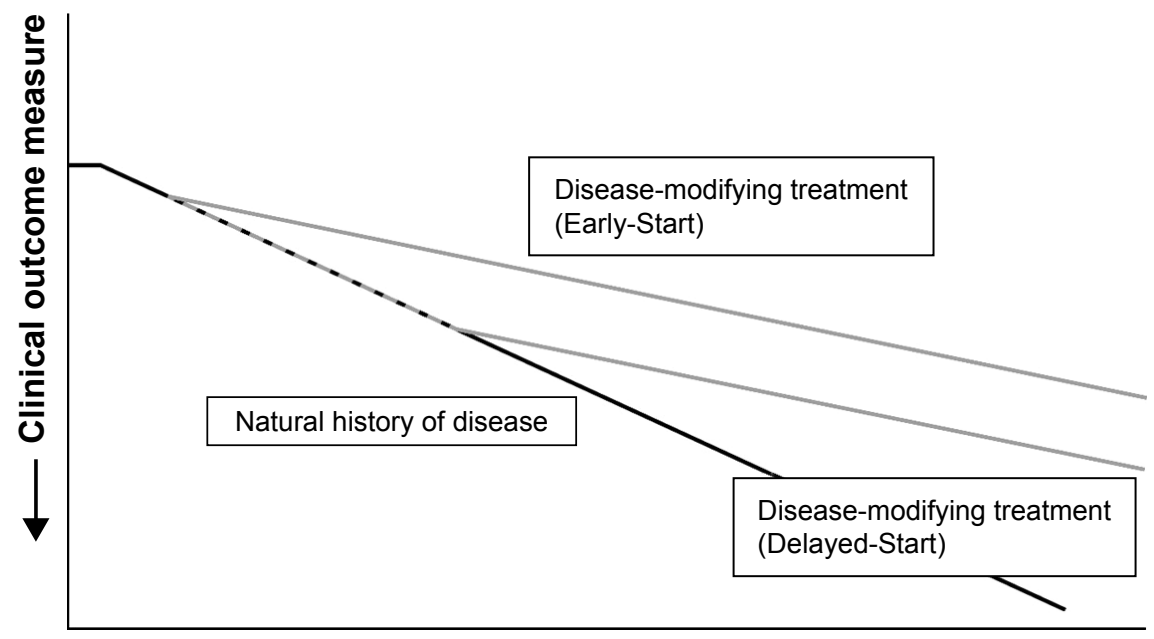

Figure 3 Change in clinical outcome measures after administration of a disease-modifying therapy.

Notes: Reproduced with permission from Taylor \& Francis. The Version of Scholarly Record of this Article is published in COPD: Journal of Chronic Obstructive Pulmonary Disease (2016), available online at: http://www.tandfonline.com/l0.1080/I54I2555.2016.1178224. This article was distributed under the terms of the Creative Commons Attribution-NonCommercial-NoDerivatives license. Disease Modification in Emphysema Related to Alpha-I Antitrypsin Deficiency, COPD: Journal of Chronic Obstructive Pulmonary Disease, Chorostowska-Wynimko J, Vol I3, pp. 807-8I5, published online: 12 May 2016, http://www.tandfonline.com reprinted by permission of the publisher. ${ }^{23}$ 
of 684 patients with a baseline $\mathrm{FEV}_{1}$ of $35 \%-49 \%$, studied over 5 years (recruited over the first 2 years and followed subsequently for a further 3 years) would be necessary to observe a $40 \%$ reduction in mortality. ${ }^{42}$ Evidence from a post hoc analysis of the RAPID program suggests a mortality benefit following AAT treatment. During the program, the time required for progressive emphysema to develop into respiratory crisis was used to simulate the life-years gained as a result of AAT replacement therapy. Respiratory crisis was defined as death, lung transplant or a crippling respiratory condition. Seven patients withdrew with an average terminal lung density of $20 \mathrm{~g} / \mathrm{L}$. Using the average baseline lung density for all subjects $(46 \mathrm{~g} / \mathrm{L})$ and the rate of decline in lung density in AAT versus placebo-treated patients, the projected time to terminal lung density was 16.9 years for those receiving AAT replacement therapy, compared with 11.3 years in the placebo group (Figure 4). This indicates a gain in life-years of $\sim 5.6$ years with AAT treatment. ${ }^{22}$ Although conducted in a small sample size, these data are supported by results from the National Heart, Lung, and Blood Institute observational study showing that patients receiving AAT replacement therapy had a greater survival than those not receiving treatment. ${ }^{37}$

These data also highlight the utility of $\mathrm{CT}$ as a clinical measure to monitor emphysema progression in AATD. It is now widely accepted that $\mathrm{CT}$ is the most sensitive measure for monitoring emphysema progression. ${ }^{24}$ Furthermore, CT has been shown to correlate with other indices, such as pulmonary function, and is a better predictor of mortality than lung function. ${ }^{27,43}$ During the RAPID clinical trial program,
CT was shown to correlate with several secondary endpoints, further validating the use of CT as a clinical endpoint. Significant correlations were observed for spirometry values, such as $\mathrm{FEV}_{1} \%$ predicted $(r=0.338, p=0.0002) .{ }^{22}$ Similar correlations between $\mathrm{FEV}_{1}$ and $\mathrm{CT}$ have been observed in other cross-sectional studies. ${ }^{26,44}$

\section{Clinical considerations for the treatment of patients with AATD}

The RAPID program, in conjunction with previous observational work and RCTs, has provided compelling evidence for the efficacy of AAT therapy. These data also highlight the importance of early detection and intervention in order to enable patients to receive appropriate treatment and preserve functional lung tissue. However, guidance for the treatment of AATD is limited; a previous statement from the American Thoracic Society (ATS)/European Respiratory Society $(\mathrm{ERS})^{45}$ precedes the RAPID program and there is a need for improved guidance on the practical aspects of AATD treatment. In view of this, during the ERS Expert Forum, the topics of monitoring AATD, identification of patients who would benefit from treatment and differences between treatment options were discussed. Considerations from these discussions are reviewed below.

\section{Monitoring patients with AATD}

There is considerable variability in the types and frequency of measures used to monitor disease progression in patients with AATD, and there is no clear consensus on baseline assessment and how and when patients should be monitored.

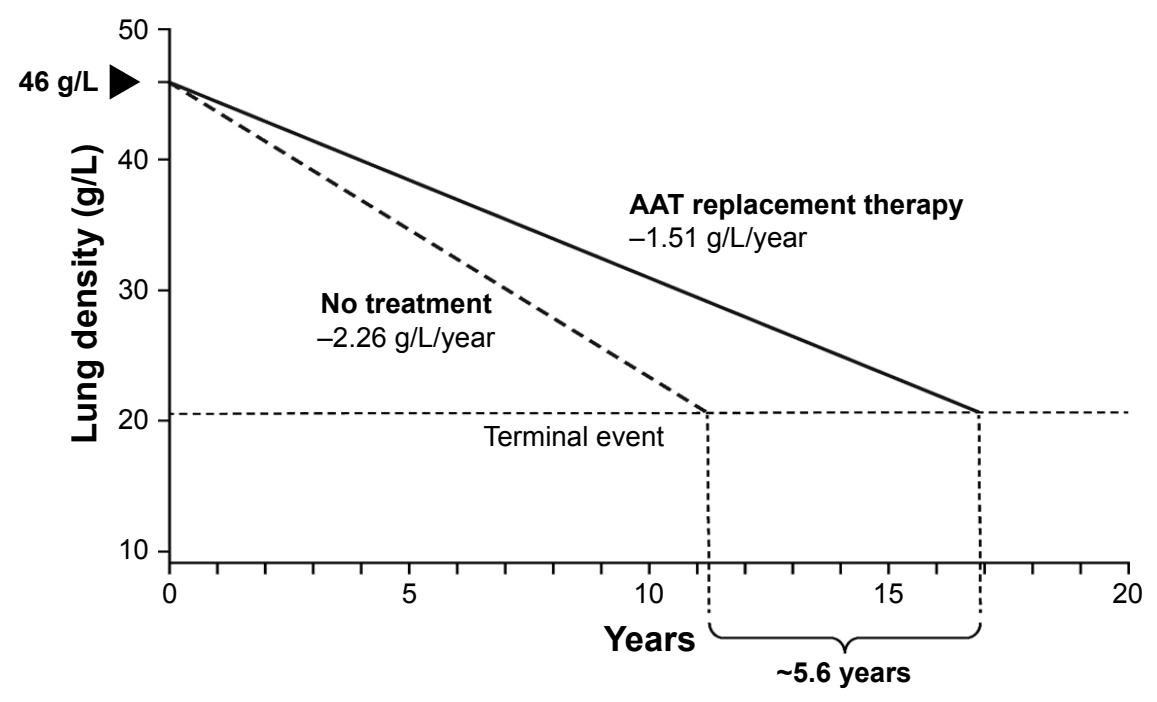

Figure 4 Extrapolation of the effect of AAT replacement therapy on the predicted time to reach terminal respiratory function in RAPID-RCT.

Notes: Reproduced from The Lancet Respiratory Medicine, Vol 5. McElvaney NG, et al. Long-term efficacy and safety of $\alpha$ I proteinase inhibitor treatment for emphysema caused by severe $\alpha$ l antitrypsin deficiency: an open-label extension trial (RAPID-OLE), Pp. 5I-60. Copyright (20I7), with permission from Elsevier. ${ }^{22}$

Abbreviations: AAT, alpha I antitrypsin; RAPID, Randomized, Placebo-controlled Trial of Augmentation Therapy in Alpha-I Proteinase Inhibitor Deficiency; RCT, randomized controlled trial. 
Guidance published by Silverman and Sandhaus recommend full pulmonary and liver function tests in an initial consultation and further annual tests, with potential consideration for initial chest radiographs and baseline CT scans. ${ }^{46}$ In contrast, the Spanish guidelines differ in the recommended frequency of spirometry and radiographic measures of lung function. Quarterly and biannual assessments are suggested, respectively, with additional annual testing of lung volume, transfer factor for carbon monoxide and liver function. ${ }^{47}$

While many guidelines suggest regularly monitoring patients using spirometric measures of lung function, such as $\mathrm{FEV}_{1}$, these measures may not be the most sensitive. In $\mathrm{AATD}_{1} \mathrm{FEV}_{1}$ has been shown to change slowly over time and is subject to a considerable degree of inter- and intra-patient variability. ${ }^{23,48}$ Intra-patient variability can be attributed to technical factors, such as instrument performance, as well as observer and subject procedural errors. Additionally, intra-patient factors, such as the extent of airway obstruction, changes in bronchial tone and diurnal variations in $\mathrm{FEV}_{1}$, can contribute to further variability. ${ }^{49-51}$ Previous analysis has revealed a mean between-test difference in $\mathrm{FEV}_{1}$ of $0.1 \pm 0.1 \mathrm{~L}$, which exceeds the volume change in $\mathrm{FEV}_{1}$ observed after intervention with AAT replacement therapy, ${ }^{36}$ as well as the annual loss of lung function in patients classed as fast decliners. ${ }^{52,53}$ These factors can make it difficult to reliably detect changes in disease progression or treatment efficacy and create difficulties when attempting to set broadly applicable $\mathrm{FEV}_{1}$ ranges on which to base treatment recommendations. ${ }^{54}$

Considering these shortcomings, other measures, including diffusing capacity of the lung for carbon monoxide $\left(\mathrm{DL}_{\mathrm{CO}}\right)$ or CT, may be more sensitive for monitoring patients with AATD. The US Food and Drug Administration has acknowledged the value of serial high-resolution CT lung densitometry as a more valuable outcome measure of the progression of emphysema and the effectiveness of AAT replacement therapy. ${ }^{55}$ This is derived from the various studies showing that CT parameters correlate with anatomic pathology and various pulmonary function tests (Table 1). Despite these results, sequential quantitative CT scans of the lungs are not recommended as part of the routine assessment of emphysema progression in the current Global Initiative for Chronic Obstructive Lung Disease guidelines. ${ }^{56}$ While quantitative CT scanning has been widely used in clinical trials, there remain a number of challenges to its wider adoption as part of standard clinical methods. These are predominantly associated with a lack of access to suitable CT scanners, the requirement for skilled operators to perform the acquisition and a lack of standardized methodologies among available CT imaging protocols. A number of studies have been dedicated to ensuring optimization and repeatability in lung densitometry measures with respect to choice of densitometric parameters, ${ }^{57}$ data calibration, ${ }^{57}$ standardization of $\mathrm{CT}$ acquisition protocol, ${ }^{43}$ patient inspiration level ${ }^{58}$ and image processing. ${ }^{59}$ A further concern regarding the wider implementation of CT scanning for determination of emphysema progression is the issue of subjecting patients to repeated doses of ionizing radiation. However, studies have already shown that low-dose CT measurements differ only marginally from those obtained with standard-dose scans. ${ }^{60}$ Furthermore, the cumulative dose for patients experiencing multiple CT scans remains fairly low. ${ }^{61}$ A typical two-view chest X-ray can expose a patient to $0.1 \mathrm{mSv}$ of radiation. Effective lowdose protocols for quantitative $\mathrm{CT}$ are possible with exposures of $\sim 0.5-1.5 \mathrm{mSv},{ }^{61}$ which is below the annual background radiation of $3 \mathrm{mSv} /$ year observed in the USA. ${ }^{62}$

In order to improve the monitoring of patients with AATD, clear consensus on the types and frequency of measurements is needed. In addition to highlighting measures that would be useful in the majority of patients (eg, FEV $\mathrm{FE}_{1}$, CT), it would also be useful to acknowledge the need to expand monitoring tests in some instances, for example, to include liver function tests or QoL questionnaires. For all patients, baseline measurements are essential to track disease progression and identify fast decliners who may obtain greater benefit from treatment.

\section{Identifying the right patient and when to initiate treatment}

Previous evidence from observational and registry studies indicated that AAT replacement treatment was most effective within certain $\mathrm{FEV}_{1}$ ranges, for example, between $30 \%$ and $65 \%$ predicted, ${ }^{37,40}$ and current guidance for treatment has been limited to patients who fall within these restrictions. This can lead to the neglect of patients outside of these parameters who may benefit from treatment. The more recently published Alpha-1 Global Foundation recommendations for the diagnosis and management of AATD in adult patients ${ }^{63}$ continue to support the treatment of patients with $\mathrm{FEV}_{1}$ between $30 \%$ and $65 \%$ and continuing therapy when the $\mathrm{FEV}_{1}$ falls below $30 \%$, when lung transplantation becomes a viable treatment option.

Evidence is beginning to emerge demonstrating that there may be value in identifying and treating patients outside of established parameters. First, numerous testing initiatives are ongoing with the aim of improving the detection of broader 
genotypes containing new deficiency alleles currently being identified. Large-scale screenings in general populations, students, newborns and blood donors, as well as new case finding strategies that target patients with COPD and asthma, will aid in the discovery of new patients in need of treatment. ${ }^{64}$ Furthermore, incorporation of SERPINA1 sequencing and/or next-generation sequencing methods in the diagnostic routine will also help recognize patients with rare and new pathologic alleles misdiagnosed by standard testing algorithms. ${ }^{65,66}$ Second, the evidence of disease modification and the potential mortality benefit with AAT replacement therapy from the RAPID program demonstrate the value of earlier treatment intervention where $\mathrm{FEV}_{1}$ is more likely to be outside of the recommended treatment bracket. This is reflected in updated recommendations from the Alpha-1 Foundation from the USA, which incorporate more inclusive parameters with broader treatment ranges. ${ }^{63}$ Indeed, the labels of second-generation products are beginning to reflect these broader parameters in the treatment recommendations. The previous statement from the ATS/ ERS is currently being updated and is likely to include recommended restrictions.

The Alpha-1 Foundation guidelines also address concerns relating to costs associated with testing and treating patients. The guidelines place a high value on complete baseline and follow-up pulmonary function testing to better identify patients with accelerated lung function decline and a low value on the costs associated with these tests. These can range from $€ 13.40$ to $€ 33$, and for sequencing can be up to $€ 150$ per test. ${ }^{67}$ Furthermore, the guidelines indicate that a higher value (compared to the cost of treatment) can be placed on the potential for AAT replacement therapy to prolong survival in patients with $\mathrm{FEV}_{1}<30 \%-65 \%$ predicted. ${ }^{63}$ The cost of augmentation therapy can range from $\$ 60,000$ to $\$ 150,000$ annually and depends on several factors including body weight, pricing and the cost of nursing care. ${ }^{46}$ Importantly, reduced symptom severity and decreased hospitalizations can help to offset the costs associated with treatment. ${ }^{68}$ Furthermore, the cost of AAT treatment is comparable or lower than that of other rare pulmonary diseases such as idiopathic pulmonary fibrosis (approximate annual drug cost for Nintedanib $=\$ 110,000$ ) or cystic fibrosis (approximate annual drug cost for Ivacaftor $=\$ 325,000) .{ }^{69}$ Due to the lower rates of lung density decline in individuals receiving intravenous AAT replacement therapy, as well as the potential to extend the time to terminal lung function as shown in the RAPID program, there is now renewed scope for the exploration of the overall cost-benefit of such a therapeutic intervention.
The disease-modifying implications of the RAPID program results based on CT densitometric parameters stress the importance of early intervention at the first signs of emphysema and the importance of targeting patients in the lower ranges of $\mathrm{FEV}_{1}$ deterioration. Updated guidance to reflect these recent findings is needed to emphasize the importance of early recognition, which allows clinicians to prevent, recognize and treat potential complications of emphysema such as hypoxemia ${ }^{70}$ and frequent exacerbations. ${ }^{71}$ Furthermore, earlier recognition will allow for the recommendation of restraint from deleterious lifestyle habits, including cigarette smoking, which are known to accelerate the progression of emphysema. Importantly, not all patients with AATD have access to replacement therapy and not all patients experience lung function decline. ${ }^{72}$ Whether AAT replacement therapy would be beneficial to all individuals with AATD is unclear. There is evidence that non-AATD patients with COPD can experience stabilization by simply giving up smoking, ${ }^{48}$ and there is anecdotal evidence for a similar effect in AATD patients. As the rate of lung density decline differs between patients with AATD, personalized treatment approaches may be beneficial. These approaches aim to restrict AAT therapy to patients who are likely to gain the most benefit, for example, "rapid decliners", who experience substantial annual $\mathrm{FEV}_{1}$ loss. ${ }^{72}$ However, there is a lack of evidence for treatment within this subgroup and limited information on how to identify them.

\section{Treatment of patients with intravenous AAT replacement and continuation of treatment}

Current licensed treatment for AATD includes weekly infusions ( $60 \mathrm{mg} / \mathrm{kg} /$ week) of AAT; a variety of preparations are available, some of which may have advantages for patients. These second-generation products offer superior purity and, hence, higher specific activity, ${ }^{73}$ which allows for faster infusion times, making treatment more convenient for patients. The differences between AAT preparations highlight a need for increased awareness of the available treatment options and the potential differences in individual patient tolerance. In addition, alternative dosing strategies, including bi-weekly dosing, higher doses or self-administration, may hold hope for improved efficacy of treatment in the future, as discussed below.

Intravenous AAT replacement therapy derived from purified pooled human plasma is currently recommended for $60 \mathrm{mg} / \mathrm{kg}$ weekly infusions by the ATS/ERS and updated US guidelines..$^{45,63}$ This is based primarily on data from early biochemical studies demonstrating the efficacy of treatment 
in maintaining serum levels above the protective threshold of $11 \mu \mathrm{M} .^{74-81}$ Data from the RAPID program reinforced these recommendations, demonstrating that $60 \mathrm{mg} / \mathrm{kg}$ weekly infusions maintained serum levels above the protective threshold and were able to significantly slow the decline in lung density. The Spanish guidelines suggest some value in alternative dosing intervals, such as $180 \mathrm{mg} / \mathrm{kg}$ every 3 weeks and $120 \mathrm{mg} / \mathrm{kg}$ every 2 weeks. $^{47}$

Alternative dosing regimens may provide a means to improve patient convenience. There is an increasing body of evidence for the safety and efficacy of alternative dosing intervals, such as bi-weekly dosing. During RAPID-RCT, patients were administered a higher bi-weekly dose of $120 \mathrm{mg} / \mathrm{kg}$ to account for periods where they may be unable to receive the normal weekly infusion (eg, during vacation). The $120 \mathrm{mg} / \mathrm{kg}$ bi-weekly dose achieved serum levels above the $11 \mu \mathrm{M}$ protective threshold and was well tolerated, causing no serious adverse events. ${ }^{82}$ In addition, regimens of $100 / 120 \mathrm{mg} / \mathrm{kg}$ every 2 weeks, 150/180 mg/kg every 3 weeks and $250 \mathrm{mg} / \mathrm{kg}$ every 4 weeks have also been studied in pharmacokinetic simulations to estimate the individual optimal dose for AAT replacement therapy. While infusions of $100 / 120 \mathrm{mg} / \mathrm{kg}$ every 2 weeks can sustain serum AAT levels above the protective threshold, ${ }^{83}$ longer infusion intervals, such as monthly infusions of $250 \mathrm{mg} / \mathrm{kg}$, failed to maintain the protective serum concentrations across the full 28 days of the dose window. ${ }^{29}$ In order to prove the efficacy and safety of alternative dosing intervals, and of higher doses, further clinical trials are ongoing. For example, the upcoming SPARTA trial (NLM identifier: NCT01983241) will aim to further explore the efficacy of double dosing regimens $(120 \mathrm{mg} / \mathrm{kg})$ administered weekly over 3 years. ${ }^{84}$

Finally, alternative means of treatment administration, such as home treatment or self-administration, may provide further options to improve convenience for patients. These methods have been employed with some degree of success; Wilke and Grohe performed a prospective study tracking seven patients over 3 years as they received nurse-based intravenous AAT replacement therapy at home. The results showed that home-based AAT replacement therapy was feasible, as there were few complications related to home infusion and less exacerbations and loss of lung function with respect to the historical cohort. ${ }^{85}$ Self-administration is also an option for some patients; this has been successfully used in a number of indications, such as hereditary angioedema ${ }^{86}$ and hemophilia, ${ }^{87,88}$ and within the USA, it is provided for a number of patients with AATD. In order to implement these measures, training and awareness resources are required to support physicians, nurses and patients. Clinicians should be aware of these improved convenience options and of the differences in available products, so as to deliver a more personalized, patient-centric approach to AATD treatment.

\section{Value of lifestyle modifications}

Although AAT replacement therapy is the only available treatment that addresses the underlying cause of AATD, symptomatic treatment and lifestyle modifications may be of benefit to patients. However, managing the care of patients beyond the prescription of AAT therapy is often overlooked by physicians. Current guidelines, although broad, make few concrete recommendations on lifestyle modifications. The current ATS/ERS statement and US guidelines take a firm stance on smoking cessation, and patients are encouraged to maintain a level of physical activity while avoiding exercise that may lead to hyperventilation. ${ }^{45,63}$ Despite the recommendation of continued physical activity, unlike the guidelines for COPD, they do not provide comprehensive practical guidance on the types, duration and frequency of exercise that may be beneficial for AATD patients.

There may be potential to transfer the recommendations provided for COPD to AATD with respect to detailed physical activity and pulmonary rehabilitation guidelines. Guidelines from the Canadian Thoracic Society recognize the importance of nonpharmacologic methods for optimal disease management, such as pulmonary rehabilitation provided by specific exercise regimes. ${ }^{89}$ Additionally, the American College of Sports Medicine recommends moderate or vigorous aerobic exercise and moderate intensity resistance training to improve the capacity to perform everyday tasks and enhance QoL (Figure 5). ${ }^{90}$ Pulmonary rehabilitation has been

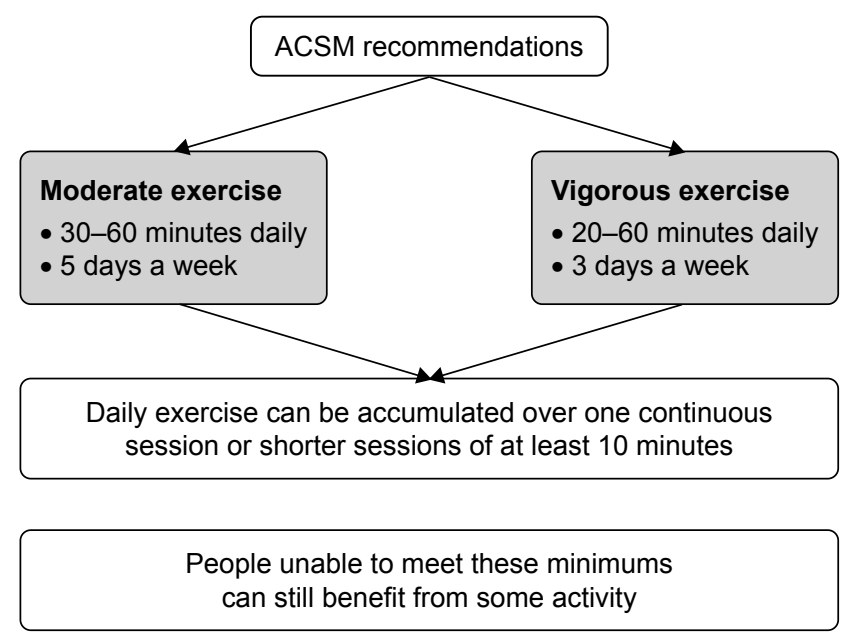

Figure 5 ACSM exercise recommendations for pulmonary rehabilitation. ${ }^{90}$ Abbreviation: ACSM, American College of Sports Medicine. 
acknowledged as a valuable treatment for those suffering from lung disease, as it can improve the lung function, general exercise stamina and QoL and facilitate a reduced burden on health care resources..$^{91,92}$ In particular, exercise capacity has been shown to be significantly related to the $\mathrm{CT}$ pixel index observed in patients with centrilobular emphysema. ${ }^{93}$ Exercise capacity has also been shown to be a better predictor of health status than other parameters based on lung imaging or physiologic impairment. ${ }^{94}$ There is, therefore, a need to provide greater guidance on pulmonary rehabilitation that is appropriate for patients with AATD. In addition, further guidance on additional measures may be warranted, including limiting the exposure to airborne pollutants (eg, passive smoking, dusts and fumes) that may aggravate the condition and ensuring the vaccination of patients against influenza, pneumococcal pneumonia and hepatitis.

\section{Future developments}

The RAPID program is the first to confirm the clinical efficacy of AAT replacement therapy. The results indicate that the goal should be to focus on how to best incorporate disease-modifying AAT therapy into current clinical practice. New US treatment recommendations from the Alpha-1 Foundation have been developed, ${ }^{63}$ which provide updated guidance on treatment of patients at earlier disease stages. Current ATS guidelines remain unchanged, and updates to the ERS statement are ongoing.

RAPID-RCT also suggested that alternative dosing such as bi-weekly infusions is well tolerated and plasma concentrations to a large extent exceed the $11 \mu \mathrm{M}$ threshold during this regimen. This has been corroborated by additional studies suggesting value in a more personalized approach to therapy regimens with respect to dose, treatment interval and potential self-administration. Upcoming clinical studies such as the SPARTA trial aim to further explore the efficacy of double dosing regimens using regional lung density as measured by CT. This study will build on the results of the RAPID program that validated CT densitometry as a valuable outcome measure for the efficacy of AAT replacement therapy. Additionally, the heterogeneous distribution of emphysema has warranted the exploration of regional lung densitometry to elucidate the relationship between regional lung density decline and the decline in overall lung function. Current and future studies exploring the standardization of CT densitometry will help develop consensus on acquisition protocols and densitometric parameters to facilitate wider use of CT methods in this clinical setting.

\section{Conclusion}

The results of the RAPID program have demonstrated the efficacy and disease-modifying effect of AAT replacement therapy. In combination with data from earlier studies, there is now a large body of evidence that supports the use of AAT therapy. Despite this, AAT replacement therapy is not currently available in all countries, and this expert review has highlighted several key areas where improvements in the diagnosis and management of AATD patients are needed.

First, increased awareness of this rare lung condition and improved utilization of screening and diagnostic methods are needed to help reduce delays or misdiagnosis. Identification of patients earlier allows them to make lifestyle modifications (eg, avoidance of aggravating factors, smoking cessation and exercise/pulmonary rehabilitation) and allows timely access to disease-modifying therapy. Updated guidance on diagnosis, lifestyle modifications and pharmacotherapy is warranted.

Second, further guidance is required to facilitate the appropriate implementation of nonpharmacologic treatment measures such as exercise and dietary modifications to promote pulmonary rehabilitation. In addition, practical recommendations for the treatment of AATD are warranted that provide guidance on alternative dosing regimens and patient-centered convenience measures, such as home treatment or self-administration.

Finally, CT densitometry provides a new opportunity to change the landscape of how disease progression and treatment efficacy for AATD are assessed. The results of the RAPID program provide new insight into the utility of CT densitometry to detect the early signs of emphysema and the occurrence of complications such as hypoxemia. Further consideration of how different CT methodologies can be applied is necessary to facilitate implementation beyond trial settings and into routine clinical assessments.

\section{Acknowledgments}

Editorial assistance was provided by Meridian HealthComms, funded by CSL Behring.

\section{Author contributions}

All authors contributed toward data analysis, drafting and revising the paper and agree to be accountable for all aspects of the work.

\section{Disclosure}

Professor McElvaney reports grants and personal fees from CSL Behring, grants, personal fees and non-financial support 
from Grifols, outside the submitted work. Professor Chapman reports grants and personal fees from AstraZeneca, grants and personal fees from Boehringer Ingelheim, grants from Baxter, grants and personal fees from CSL Behring, grants and personal fees from Grifols, grants from GlaxoSmithKline, grants and personal fees from Sanofi, grants and personal fees from Genentech, grants and personal fees from Kamada, grants from Amgen, grants and personal fees from Roche, grants and personal fees from Novartis, personal fees from Merck and personal fees from CIHR-GSK Research Chair in Respiratory Health Care Delivery, UHN, during the conduct of the study. Professor Koczulla reports personal fees from CSL Behring, outside the submitted work. Dr Ferrarotti reports personal fees from CSL Behring, outside the submitted work. The authors report no other conflicts of interest in this work.

\section{References}

1. Sharafkhaneh A, Hanania NA, Kim V. Pathogenesis of emphysema: from the bench to the bedside. Proc Am Thorac Soc. 2008;5(4):475-477.

2. Bernspång E, Sveger T, Piitulainen E. Respiratory symptoms and lung function in 30-year-old individuals with alpha-1-antitrypsin deficiency. Respir Med. 2007;101(9):1971-1976.

3. National Human Genome Research Institute. Learning about alpha-1 antitrypsin deficiency (AATD); 2012. Available from: https://www. genome.gov/19518992/learning-about-alpha1-antitrypsin-deficiencyaatd/. Accessed October 23, 2017.

4. Brantly ML, Paul LD, Miller BH, Falk RT, Wu M, Crystal RG. Clinical features and history of the destructive lung disease associated with alpha-1-antitrypsin deficiency of adults with pulmonary symptoms. Am Rev Respir Dis. 1988;138(2):327-336.

5. Abboud RT, Nelson TN, Jung B, Mattman A. Alpha(1)-antitrypsin deficiency: a clinical-genetic overview. Appl Clin Genet. 2011;4:55-65.

6. Brantly ML, Wittes JT, Vogelmeier CF, Hubbard RC, Fells GA, Crystal RG. Use of a highly purified alpha 1-antitrypsin standard to establish ranges for the common normal and deficient alpha 1-antitrypsin phenotypes. CHEST. 1991;100(3):703-708.

7. Fregonese L, Stolk J. Hereditary alpha-1-antitrypsin deficiency and its clinical consequences. Orphanet J Rare Dis. 2008;3(1):16.

8. Stockley RA. Alpha-1-antitrypsin deficiency: what next? Thorax. 2000; 55(7):614-618.

9. de Serres FJ. Worldwide racial and ethnic distribution of $\alpha 1$-antitrypsin deficiency: summary of an analysis of published genetic epidemiologic surveys. Chest. 2002;122(5):1818-1829.

10. Blanco I, Fernández E, Bustillo EF. Alpha-1-antitrypsin PI phenotypes S and $\mathrm{Z}$ in Europe: an analysis of the published surveys. Clin Genet. 2001;60(1):31-41.

11. Craig TJ. Suspecting and testing for alpha-1 antitrypsin deficiency - an allergist's and/or immunologist's perspective. J Allergy Clin Immunol Pract. 2015;3(4):506-511.

12. Stoller JK, Aboussouan LS. A review of alpha1-antitrypsin deficiency. Am J Respir Crit Care Med. 2012;185(3):246-259.

13. Alsaeedi A, Sin DD, McAlister FA. The effects of inhaled corticosteroids in chronic obstructive pulmonary disease: a systematic review of randomized placebo-controlled trials. Am J Med. 2002;113(1): 59-65.

14. Aguilaniu B. Impact of bronchodilator therapy on exercise tolerance in COPD. Int J Chron Obstruct Pulmon Dis. 2010;5:57-71.

15. Colp C, Pappas J, Moran D, Lieberman J. Variants of alpha 1-antitrypsin in Puerto Rican children with asthma. Chest. 1993;103(3): $812-815$.
16. O'Brien ML, Buist NR, Murphey WH. Neonatal screening for alpha1antitrypsin deficiency. J Pediatr. 1978;92(6):1006-1010.

17. Silverman EK, Miletich JP, Pierce JA, et al. Alpha-1-antitrypsin deficiency. High prevalence in the St. Louis area determined by direct population screening. Am Rev Respir Dis. 1989;140(4):961-966.

18. de Serres FJ, Blanco I. Prevalence of alpha1-antitrypsin deficiency alleles $\mathrm{PI}{ }^{*} \mathrm{~S}$ and $\mathrm{PI}{ }^{*} \mathrm{Z}$ worldwide and effective screening for each of the five phenotypic classes PI*MS, PI*MZ, PI*SS, PI*SZ, and PI*ZZ: a comprehensive review. Ther Adv Respir Dis. 2012;6(5): 277-295.

19. Stoller JK, Sandhaus RA, Turino G, Dickson R, Rodgers K, Strange C. Delay in diagnosis of $\alpha 1$-antitrypsin deficiency: a continuing problem. Chest. 2005;128(4):1989-1994.

20. Greulich T, Vogelmeier CF. Alpha-1-antitrypsin deficiency: increasing awareness and improving diagnosis. Ther Adv Respir Dis. 2016; 10(1):72-84.

21. Chapman KR, Burdon JG, Piitulainen E, et al. Intravenous augmentation treatment and lung density in severe alphal antitrypsin deficiency (RAPID): a randomised, double-blind, placebo-controlled trial. Lancet. 2015;386(991):360-368.

22. McElvaney NG, Burdon J, Holmes M, et al. Long-term efficacy and safety of a-1 proteinase inhibitor treatment for emphysema caused by severe a-1 antitrypsin deficiency: an open-label extension trial (RAPIDOLE). Lancet Respir Med. 2017;5(1):51-60.

23. Chorostowska-Wynimko J. Disease modification in emphysema related to alpha-1 antitrypsin deficiency. COPD. 2016;13(6):807-815.

24. Parr DG, Dirksen A, Piitulainen E, Deng C, Wencker M, Stockley RA. Exploring the optimum approach to the use of CT densitometry in a randomised placebo-controlled study of augmentation therapy in alpha 1-antitrypsin deficiency. Respir Res. 2009;10(1):75.

25. Stolk J, Putter H, Bakker EM, et al. Progression parameters for emphysema: a clinical investigation. Respir Med. 2007;101(9):1924-1930.

26. Parr DG, Stoel BC, Stolk J, Stockley RA. Validation of computed tomographic lung densitometry for monitoring emphysema in $\alpha 1$-antitrypsin deficiency. Thorax. 2006;61(6):485-490.

27. Stockley RA, Parr DG, Piitulainen E, Stolk J, Stoel BC, Dirksen A. Therapeutic efficacy of alpha-1 antitrypsin augmentation therapy on the loss of lung tissue: an integrated analysis of 2 randomised clinical trials using computed tomography densitometry. Respir Res. 2010;11(1):136.

28. Rahaghi FF, Miravitlles M. Long-term clinical outcomes following treatment with alpha 1-proteinase inhibitor for COPD associated with alpha-1 antitrypsin deficiency: a look at the evidence. Respir Res. 2017; 18(1):105

29. Dirksen A, Dijkman J, Madsen F, et al. A Randomized Clinical Trial of $\alpha 1$-Antitrypsin Augmentation Therapy. Am J Respir Crit Care Med. 1999;160(5):1468-1472.

30. Dirksen A, Piitulainen E, Parr DG, et al. Exploring the role of CT densitometry: a randomised study of augmentation therapy in alpha1antitrypsin deficiency. Eur Respir J. 2009;33(6):1345-1353.

31. Dowson L, Guest P, Stockley R. Longitudinal changes in physiological, radiological, and health status measurements in $\alpha 1$-antitrypsin deficiency and factors associated with decline. Am J Respir Crit Care Med. 2001;164(10):1805-1809.

32. Dawkins PA, Dowson LJ, Guest PJ, Stockley RA. Predictors of mortality in alpha1-antitrypsin deficiency. Thorax. 2003;58(12): 1020-1026.

33. Stolk J, Ng WH, Bakker ME, et al. Correlation between annual change in health status and computer tomography derived lung density in subjects with $\alpha 1$-antitrypsin deficiency. Thorax. 2003;58(12): 1027-1030.

34. Parr DG, Stoel BC, Stolk J, Stockley RA. Pattern of emphysema distribution in $\alpha 1$-antitrypsin deficiency influences lung function impairment. Am J Respir Crit Care Med. 2004;170(11):1172-1178.

35. Chapman KR, Bradi AC, Paterson D, Navickis RJ, Wilkes MM. Slower lung function decline during augmentation therapy in patients with alpha1-antitrypsin deficiency (A1ATD): results from the Canadian AIR registry. Proc Am Thorac Soc. 2005;2:A808. 
36. Seersholm N, Wencker M, Banik N, et al. Does alpha1-antitrypsin augmentation therapy slow the annual decline in FEV1 in patients with severe hereditary alphal-antitrypsin deficiency? Wissenschaftliche Arbeitsgemeinschaft zur Therapie von Lungenerkrankungen (WATL) alpha1-AT study group. Eur Respir J. 1997;10(10):2260-2263.

37. The Alpha-1-Antitrypsin Deficiency Registry Study Group. Survival and FEV1 decline in individuals with severe deficiency of $\alpha 1$-antitrypsin. Am J Respir Crit Care Med. 1998;158(1):49-59.

38. Tonelli AR, Rouhani F, Li N, Schreck P, Brantly ML. Alpha-1antitrypsin augmentation therapy in deficient individuals enrolled in the alpha-1 foundation DNA and tissue bank. Int J Chron Obstruct Pulmon Dis. 2009;4:443-452.

39. Wencker M, Fuhrmann B, Banik N, Konietzko N, Wissenschaftliche Arbeitsgemeinschaft zur Therapie von L. Longitudinal follow-up of patients with alpha(1)-protease inhibitor deficiency before and during therapy with IV alpha(1)-protease inhibitor. Chest. 2001;119(3):737-744.

40. Chapman KR, Stockley RA, Dawkins C, Wilkes MM, Navickis RJ. Augmentation therapy for alphal antitrypsin deficiency: a meta-analysis. COPD. 2009;6(3):177-184.

41. Halpin DMG, Tashkin DP. Defining disease modification in chronic obstructive pulmonary disease. COPD. 2009;6(3):211-225.

42. Schluchter MD, Stoller JK, Barker AF, et al. Feasibility of a clinical trial of augmentation therapy for alpha(1)-antitrypsin deficiency. The Alpha 1-Antitrypsin Deficiency Registry Study Group. Am J Respir Crit Care Med. 2000;161(3 Pt 1):796-801.

43. Stoel BC, Stolk J. Optimization and standardization of lung densitometry in the assessment of pulmonary emphysema. Invest Radiol. 2004; 39(11):681-688

44. Gevenois PA, De Vuyst P, de Maertelaer V, et al. Comparison of computed density and microscopic morphometry in pulmonary emphysema. Am J Respir Crit Care Med. 1996;154(1):187-192.

45. American Thoracic Society/European Respiratory Society. Standards for the diagnosis and management of individuals with alpha-1 antitrypsin deficiency. Am J Respir Crit Care Med. 2003;168(7):818-900.

46. Silverman EK, Sandhaus RA. Alpha1-antitrypsin deficiency. N Engl J Med. 2009;360(26):2749-2757.

47. Vidal R, Blanco I, Casas F, Jardi R, Miravitlles M. Committee on the National Registry of Individuals with Alpha-1 Antitrypsin D. [Guidelines for the diagnosis and management of alpha-1 antitrypsin deficiency]. Arch Bronconeumol. 2006;42(12):645-659.

48. Anthonisen NR, Connett JE, Kiley JP, et al. Effects of smoking intervention and the use of an inhaled anticholinergic bronchodilator on the rate of decline of fev1: the lung health study. JAMA. 1994;272(19): 1497-1505.

49. Donohue JF. Minimal clinically important differences in COPD lung function. COPD. 2005;2(1):111-124.

50. Herpel LB, Kanner RE, Lee SM, et al. Variability of spirometry in chronic obstructive pulmonary disease. Am J Respir Crit Care Med. 2006; 173(10):1106-1113.

51. Enright PL, Connett JE, Kanner RE, Johnson LR, Lee WW. Spirometry in the lung health study: II. Determinants of short-term intraindividual variability. Am J Respir Crit Care Med. 1995;151(2):406-411.

52. Wise RA, Connett J, Kurnow K, et al. Selection of spirometric measurements in a clinical trial, the Lung Health Study. Am J Respir Crit Care Med. 1995;151(3 Pt 1):675-681.

53. Washko GR. Rate of decline in FEV1: is emphysema the culprit? Am J Respir Crit Care Med. 2012;185(1):2-3.

54. Crapo RO, Jensen RL. Standards and interpretive issues in lung function testing. Respir Care. 2003;48(8):764-772.

55. U.S. Food and Drug Administration (FDA). Clinical and surrogate endpoints for evaluating efficacy of alpha1-proteinase inhibitor (human) augmentation therapy. Blood products advisory committee 95 th meeting July 20-21, 2009.

56. Vogelmeier CF, Criner GJ, Martinez FJ, et al. Global strategy for the diagnosis, management, and prevention of chronic obstructive lung disease 2017 report. GOLD executive summary. Am J Respir Crit Care Med. 2017;195(5):557-582.
57. Parr DG, Stoel BC, Stolk J, Nightingale PG, Stockley RA. Influence of calibration on densitometric studies of emphysema progression using computed tomography. Am J Respir Crit Care Med. 2004;170(8): 883-890.

58. Lamers R, Kemerink G, Drent M, van Engelshoven J. Reproducibility of spirometrically controlled CT lung densitometry in a clinical setting. Eur Respir J. 1998;11(4):942-945.

59. Friedman PJ. Imaging studies in emphysema. Proc Am Thorac Soc. 2008;5(4):494-500.

60. Gierada DS, Pilgram TK, Whiting BR, et al. Comparison of standardand low-radiation-dose CT for quantification of emphysema. AJR Am J Roentgenol. 2007;188(1):42-47.

61. Mets OM, de Jong PA, van Ginneken B, Gietema HA, Lammers JWJ. Quantitative computed tomography in COPD: possibilities and limitations. Lung. 2012;190(2):133-145.

62. Brenner DJ, Doll R, Goodhead DT, et al. Cancer risks attributable to low doses of ionizing radiation: assessing what we really know. Proc Natl Acad Sci U S A. 2003;100(24):13761-13766.

63. Sandhaus RA, Turino G, Brantly ML, et al. The diagnosis and management of alpha-1 antitrypsin deficiency in the adult. Chronic Obstr Pulm Dis (Miami). 2016;3(3):668-682.

64. Ferrarotti I, Poplawska-Wisniewska B, Trevisan MT, et al. How can we improve the detection of alpha1-antitrypsin deficiency? PLoS One. 2015;10(8):e0135316.

65. Ferrarotti I, Scabini R, Campo I, et al. Laboratory diagnosis of alpha1antitrypsin deficiency. Transl Res. 2007;150(5):267-274.

66. Kueppers F, Sanders C. State-of-the-art testing for alpha-1 antitrypsin deficiency. Allergy Asthma Proc. 2017;38(2):108-114.

67. Miravitlles M, Herr C, Ferrarotti I, et al. Laboratory testing of individuals with severe alpha1-antitrypsin deficiency in three European centres. Eur Respir J. 2010;35(5):960-968.

68. Barros-Tizon JC, Torres ML, Blanco I, Martinez MT; Investigators of the r EXAsg. Reduction of severe exacerbations and hospitalization-derived costs in alpha-1-antitrypsin-deficient patients treated with alpha-1-antitrypsin augmentation therapy. Ther Adv Respir Dis. 2012;6(2):67-78.

69. GoodRX. 2017. Available from: https://www.goodrx.com. Accessed October 26, 2017.

70. Kent BD, Mitchell PD, McNicholas WT. Hypoxemia in patients with COPD: cause, effects, and disease progression. Int J Chron Obstruct Pulmon Dis. 2011;6:199-208.

71. Teschler H. Long-term experience in the treatment of $\alpha 1$-antitrypsin deficiency: 25 years of augmentation therapy. Eur Respir Rev. 2015; 24(135):46.

72. Stockley RA, Edgar RG, Pillai A, Turner AM. Individualized lung function trends in alpha-1-antitrypsin deficiency: a need for patience in order to provide patient centered management? Int J Chron Obstruct Pulmon Dis. 2016;11:1745-1756.

73. Boerema DJ, An B, Gandhi RP, et al. Biochemical comparison of four commercially available human alpha1-proteinase inhibitors for treatment of alpha1-antitrypsin deficiency. Biologicals. 2017; pii:S1045-1056(17)30105-30107.

74. Gadek JE, Klein HG, Holland PV, Crystal RG. Replacement therapy of alpha 1-antitrypsin deficiency. Reversal of protease-antiprotease imbalance within the alveolar structures of PiZ subjects. J Clin Invest. 1981;68(5):1158-1165.

75. Wewers MD, Casolaro MA, Sellers SE, et al. Replacement therapy for alpha 1-antitrypsin deficiency associated with emphysema. $N$ Engl J Med. 1987;316(17):1055-1062.

76. Barker AF, Iwata-Morgan I, Oveson L, Roussel R. Pharmacokinetic study of alpha1-antitrypsin infusion in alpha1-antitrypsin deficiency. Chest. 1997;112(3):607-613.

77. Hubbard RC, Sellers S, Czerski D, Stephens L, Crystal RG. Biochemical efficacy and safety of monthly augmentation therapy for alpha 1-antitrypsin deficiency. JAMA. 1988;260(9):1259-1264.

78. Stoller JK, Rouhani F, Brantly M, et al. Biochemical efficacy and safety of a new pooled human plasma alpha(1)-antitrypsin, Respitin. Chest. 2002;122(1):66-74. 
79. Stocks JM, Brantly M, Pollock D, et al. Multi-center study: the biochemical efficacy, safety and tolerability of a new alpha1-proteinase inhibitor, Zemaira. COPD. 2006;3(1):17-23.

80. Campos MA, Kueppers F, Stocks JM, et al. Safety and pharmacokinetics of $120 \mathrm{mg} / \mathrm{kg}$ versus $60 \mathrm{mg} / \mathrm{kg}$ weekly intravenous infusions of alpha-1 proteinase inhibitor in alpha-1 antitrypsin deficiency: a multicenter, randomized, double-blind, crossover study (SPARK). COPD. 2013; 10(6):687-695.

81. Sandhaus RA, Stocks J, Rouhani FN, Brantly M, Strauss P. Biochemical efficacy and safety of a new, ready-to-use, liquid alpha-1-proteinase inhibitor, GLASSIA (alpha1-proteinase inhibitor (human), intravenous). COPD. 2014;11(1):17-25.

82. Seersholm N, Sandhaus R, Chapman KR, et al. Safety of bi-weekly infusion of A1-PI augmentation therapy in RAPID. Eur Respir J. 2015;46(59):PA999.

83. Soy D, de la Roza C, Lara B, Esquinas C, Torres A, Miravitlles M. Alpha-1-antitrypsin deficiency: optimal therapeutic regimen based on population pharmacokinetics. Thorax. 2006;61(12): 1059-1064.

84. Sorrells S, Camprubi S, Griffin R, Chen J, Ayguasanosa J. SPARTA clinical trial design: exploring the efficacy and safety of two dose regimens of alpha1-proteinase inhibitor augmentation therapy in alpha1antitrypsin deficiency. Respir Med. 2015;109(4):490-499.

85. Wilke A, Grohe C. Prospective evaluation of clinical parameters of AAT patients with i. v. prolastin therapy in a homecare setting. Pneumologie. 2013;67(10):545-550.
86. Craig TJ. Recent advances in hereditary angioedema self-administration treatment: summary of an international hereditary angioedema expert meeting. Int Arch Allergy Immunol. 2013;161(Suppl 1):26-27.

87. Carr ME Jr. Future directions in hemostasis: normalizing the lives of patients with hemophilia. Thromb Res. 2010;125:S78-S81.

88. Oyesiku JOO. Home treatment of haemophilia patients with inhibitors. Haemophilia. 2011;17(2):173-178.

89. Marciniuk DD, Hernandez P, Balter M, et al. Alpha-1 antitrypsin deficiency targeted testing and augmentation therapy: a Canadian Thoracic Society clinical practice guideline. Can Respir J. 2012;19(2): 109-116.

90. Garber CE, Blissmer B, Deschenes MR, et al. Quantity and quality of exercise for developing and maintaining cardiorespiratory, musculoskeletal, and neuromotor fitness in apparently healthy adults: guidance for prescribing exercise. Med Sci Sports Exerc. 2011;43(7):1334-1359.

91. Gosselink R, Troosters T, Decramer M. Peripheral muscle weakness contributes to exercise limitation in COPD. Am J Respir Crit Care Med. 1996;153(3):976-980.

92. Ries AL, Make BJ, Reilly JJ. Pulmonary rehabilitation in emphysema. Proc Am Thorac Soc. 2008;5(4):524-529.

93. Jones JH, Zelt JT, Hirai DM, et al. Emphysema on thoracic CT and exercise ventilatory inefficiency in mild-to-moderate COPD. COPD. 2017;14(2):210-218

94. Dowson L, Newall C, Guest P, Hill S, Stockley R. Exercise capacity predicts health status in $\alpha 1$-antitrypsin deficiency. Am J Respir Crit Care Med. 2001;163(4):936-941.
International Journal of COPD

\section{Publish your work in this journal}

The International Journal of COPD is an international, peer-reviewed journal of therapeutics and pharmacology focusing on concise rapid reporting of clinical studies and reviews in COPD. Special focus is given to the pathophysiological processes underlying the disease, intervention programs, patient focused education, and self management protocols.

\section{Dovepress}

This journal is indexed on PubMed Central, MedLine and CAS. The manuscript management system is completely online and includes a very quick and fair peer-review system, which is all easy to use. Visit http://www.dovepress.com/testimonials.php to read real quotes from published authors. 